\title{
The Rise of Uber and Regulating the Disruptive Innovator
}

\author{
Geoffrey Dudley, David Banister and Tim Schwanen \\ Transport Studies Unit, University of Oxford
}

\begin{abstract}
The ride-hailing company Uber has achieved extremely rapid global expansion by means of out manoeuvring governments, regulators and competitors. The rise of the company has been based on a deliberate strategy of acting as a market disruptive innovator through a user friendly technology and making use of the 'sharing economy.' These attributes are not unique, but are distinctively augmented by a relentless expansionary ambition, and an ability to maintain its capacity to innovate. Uber has generated great political controversy, but the challenge for governments and regulators is to embrace the benefits of the disruptive innovator, while adopting an approach that takes into account the full range of impacts. For Uber, the challenge is to maintain its expansionary style as a disruptive innovator, while also redefining on its terms the political and public debate. The case study of London provides important insights into the dynamics of these processes.
\end{abstract}

Keywords: Uber, taxi, technology, disruptive, innovator, London.

\section{The 'Uberisation' Phenomenon}

In 2009, Uber was founded in San Francisco, initially with the intention of challenging what was generally considered to be the city's inefficient and inadequate taxi service. Since then, its strategy of relentless and audacious growth has enabled it rapidly to spread its services worldwide, so that by 2017 it operates in more than seventy countries, with around $\$ 16$ billion invested in the company since its inception. The size of its expansion is illustrated by the estimated valuation given it of $\$ 70$ billion, making it the world's most valuable privately held technology company. The rise of the company has wide implications that cover not only transport, but also changing models of business and employment, urban planning issues, and patterns of mobility in the twenty first century. A remarkable feature of the rise of Uber, however, is how it has been based on a deliberate strategy of acting as a market 'disruptive innovator' (1). It therefore provides a case study in how to exploit weaknesses in competitors, and in regulatory systems that have been compelled to behave not only in a reactionary manner, but also with frameworks that were never designed to deal with the types of technological and operational challenges presented by Uber. The challenge for Uber is to maintain its expansion as a disruptive innovator through proactively redefining the political and public debate.

The successful expansion of Uber has been based on a deceptively simple use of modern technology, in which the initial bookings, the route to be taken, the calculation of fares, and finally payment, are all made by means of a smart phone app. In operational terms, this technological base is combined with the economic concept of the 'sharing economy,' which aims to bring suppliers and consumers together by making use of spare capacity. In the case of Uber, this means that, given that a motor vehicle is typically idle for over 90 per cent of the time, the driver of a private car can 
download the Uber app, and be put in touch with customers who are using their own Uber smart phone app. Technology combined with the 'sharing economy' should mean a more efficient matching of supply and demand than for traditional taxi services. In addition, Uber employs variable pricing that can be applied to deal with periods of peak demand, while both driver and customer provide ratings for each other. The ability of Uber to challenge and often undercut the incumbent taxi operators has inevitably caused fierce opposition to its services in many countries. Particularly for regulatory purposes, Uber seeks to differentiate itself from its rivals by describing itself as a technology platform rather than a taxi company, while it classifies its drivers not as employees, but as 'registered partners.'

It must be stressed, however, that the type of service provided by Uber is far from unique, and indeed in San Francisco itself, rival companies Lyft and Sidecar provided app based services similar to those introduced by Uber in 2010. Lyft remains a major competitor in the United States, while Uber has faced major regional competition from such companies as Grab in south east Asia, Gett in Israel, and Ola in India. In China, competition has been particularly fierce. Uber poured huge resources into this market, but in 2016 was compelled to merge with its chief rival Didi Chuxing. Despite the size of its operations, the losses incurred in China and other countries have thrown doubt on Uber's long-term ability to make a profit. Uber has been most successful in large urban areas, but it is now building alliances with the public sector, particularly in the USA, so that it can expand into suburban and smaller urban areas.

In many cities and countries Uber has adopted an invasive approach, which has sought to bypass regulatory regimes. This has been particularly evident in Europe, where Uber has fought fierce battles with governments, regulators and established taxi operators in France, Germany, Belgium, and Italy, while in Hungary in 2016 Uber was effectively declared illegal and thrown out of the country by its regulators. The serious political dilemma for governments and regulators is that, while Uber provides an efficient and relatively cheap service that is popular with consumers, it can also threaten the status and existence of established operators, and make regulatory regimes appear ineffective. Similarly, by tapping into unused capacity, Uber can act as an important creator of jobs. At the same time, its refusal to treat drivers as employees can cause tensions in terms of hours worked, the payment of benefits, and wider social security.

The extent to which Uber has embedded itself in public consciousness is indicated in how the word 'uberisation' has come to be applied to any sector that apparently adopts the distinctive mix of modern technology with the principles of the 'sharing economy.' For Uber itself, however, its expansion illustrates the complexities of how governments and their regulatory regimes come to terms with innovative operators that do not fit standard templates, and challenge established perceptions of organisation, employment, and patterns of life. Uber has now spread its services to most UK cities, but London provides a notable case study in that, unlike in many European cities, from the outset its services were officially licensed, so that the regulator, Transport for London (TfL), has sought to find an accommodation with Uber, while at the same time facing fierce opposition from the long established and iconic black cab operators. Nevertheless, Uber has retained the style of a disruptive market innovator, and while this has created an ambivalent relationship with the 
regulator, it has allowed the company to continue its growth in the city and to consolidate its operational position.

\section{Uber in London and Success as a Disruptive Innovator}

Uber commenced operations in London in 2012, relatively early in its lifetime, and unlike in many European cities, from the outset its standard UberX service was officially registered by TfL (Uber also runs a number of higher grade services). In 2012, London staged the Olympic Games, and TfL feared that there might be insufficient transport capacity to meet the expected demand. Uber therefore might have been seen as a temporary expedient, but within two years the company's rapid growth in the capital was causing great unrest on the part of the established operators, particularly in the case of the plying for hire black cabs. Plying for hire vehicles are those that can be hailed on the street by customers and also picked up from cab ranks, while private hire vehicles (the category that included Uber) must be pre booked. Private hire vehicles, often referred to as minicabs, had been an established, if controversial, part of the London transport system since the 1960s, and in themselves therefore tended to create an adversarial relationship with the plying for hire system. However, what initially distinguished the Uber service was the novelty of its app, and its ability to undercut the fares of its rivals by employing the principles of the 'sharing economy,' where the drivers supplied their own vehicles, and had flexibility in terms of the hours they worked. However, as we have noted, Uber could not copyright its type of service, so that, for example, over time many of the black cabs themselves have adopted their own apps (in 2016 Uber offered its own app to the black cab drivers, but this offer was refused).

Uber therefore required something more to ensure its success and continued growth, and in this respect it has exploited its brand as a perpetual innovator that is challenging the status quo. In this respect, it has skilfully out-manoeuvred both TfL and the established operators, thereby firmly embedding its name and image in the public consciousness. Consequently, being a market disruptive innovator provides the political opportunity to exploit rules that were framed in another age, and to bypass established forums by direct appeals for public support. For a regulator such as TfL, there is a delicate balance to be struck between wishing to encourage innovation and services that apparently have wide public support, with sensitivity to the interests of established operators, and to the provision of rules that provide fair competition.

Significantly, the black cab drivers and their representative body, the Licensed Taxi Drivers Association (LTDA), have aimed their protests chiefly at TfL rather than Uber itself, on the grounds that it is the job of the regulator to ensure that innovative services remain within the bounds of what they judge to be fair competition. The dispute first flared into public view in June 2014, when an estimated 5,000 black cabs blocked the streets of central London for several hours. The protest was specifically aimed at TfL and London Mayor Boris Johnson, who the LTDA accused of being too friendly and accommodating towards Uber, and that TfL was 'afraid of Uber's money.' In reply, TfL said that they had subjected Uber to its largest ever compliance investigation, and found that its drivers held the relevant licences and insurance. It was notable that the London protest was co-ordinated with similar demonstrations in Paris, Madrid, Barcelona, Berlin, Milan, and Rome, and indicated the degree to which Uber had already become a major disruptive force across Europe. However, the 
difficulties for TfL and the black cab operators, and Uber's flare for self-publicity, was demonstrated in that the company claimed the protests had made the public more aware of their distinctive brand and style of operation, and that while the demonstrations had been going on demand for their services had risen by 850 per cent (2).

The demonstrations had no effect on the growth of Uber, and by 2015 it was estimated that the number of private hire vehicles in London had increased by nearly a fifth in the previous year to more than 78,000. Much of this rise was accounted for by Uber, which had 14,000 drivers in the capital, making it the largest provider of private hire vehicles in the city (3). Further black cab protests took place during 2015 and 2016, and in September 2015 the London Mayor's question time (where London assembly members periodically hold the Mayor to account) was disrupted when scuffles broke out with black cab drivers protesting about the legality of Uber. Mayor Boris Johnson referred to the protestors as 'Luddites,' but was clearly growing concerned at the protests, and had called on the government to exercise their powers to restrict the numbers of private hire vehicles on the streets of London. For its part, the government was clearly aware of the rising popularity of Uber, and persistently refused to take any action. A consistent advantage for Uber is that, having achieved a certain critical mass in terms of cars and drivers on the streets, restricting their growth becomes politically sensitive in terms of apparently frustrating public demand.

Apart from its public popularity, a further fundamental difficulty for both regulators and established operators posed by a technological innovator such as Uber is the challenge it presents to long established working practices and regulatory frameworks. In the case of the black cabs, a bedrock and rite of passage to entry for drivers is 'the Knowledge,' whereby candidates spend up to four years learning their way around London's 25,000 streets, and then must pass a final examination. Critics claim that modern satellite navigation systems, such as those employed by the Uber app, make 'the Knowledge' redundant. Defenders of the established system claim that no satellite navigation system can match the detailed insights and expertise required for 'the Knowledge,' but as a rite of passage it clearly is an anachronism.

Significantly, in 2015, one of the principal training schools, the Knowledge Point College, announced its imminent closure, blaming competition from Uber and London's high property prices. In the event, the College was saved by financial support from cab manufacturer the London Taxi Company, but its threatened demise indicated the fundamental challenges Uber offers to the distinctive identity of the established operators.

Similarly, in terms of regulation, the rise of Uber indicated the vulnerability of regimes framed in an age long before modern technological innovations. The London taxi regulations therefore continued to rest on foundations originally laid in the nineteenth century, and TfL discovered that it was difficult to fit Uber technology to these rules. In making their case about the illegality of Uber, the black cab drivers had claimed that the company contravened section eleven of the 1998 Private Hire Vehicles (London) Act, which stipulates that no private hire vehicle should be equipped with a taximeter, and that the Uber app constituted a taximeter. In terms of the Act, only a plying for hire cab is legally entitled to carry a taximeter, which gives a running price for the ride, based on time and distance. 
By 2015, TfL had clearly become politically sensitive to the challenges facing the black cabs, and so the regulator brought a high court case against Uber and other similar private hire operators, claiming that the app constituted an illegal taximeter. However, the High Court ruled that the app was legal, and could not be classed as a taximeter. Uber was therefore able to use its position as a technological disruptive innovator to its great advantage, while giving the taxi regulatory regime an image of being out of date, and unable to cope with modern technologies. Politically, this was a major blow for both TfL and the black cab operators, as it publicly demonstrated both the rising strength of Uber, and the difficulties in restricting its continued growth.

Having been frustrated in the legal arena, TfL then attempted to clamp down on Uber by introducing a series of proposals, including a requirement that private hire vehicles would have to wait five minutes after a booking before picking up a customer. This would have handicapped Uber in the use of its app, while other proposals included preventing operators from showing vehicles that were available for immediate hire by means of an app, and controls that threatened Uber's plans to introduce ride sharing services for its cars. Perhaps in response to Uber's attacks on the credibility of 'the Knowledge,' TfL also sought to make the topographical test taken by private hire drivers more difficult. TfL began a consultation process, but Uber responded by launching an intense lobbying campaign to win public and political support for its services. Most notably, this included a public petition that eventually was signed by 200,000 people, while a number of business organisations, including the Institute of Directors, came out in support of Uber. As TfL had expanded its case against Uber to the High Court, so Uber itself sought new arenas to counter these challenges. By widening the debate to new issues and arenas, each side battled to politically outflank the other.

Perhaps of most significance in terms of political weight, however, was an intervention by the chief executive of the UK regulatory body the Competition and Markets Authority. He warned that the TfL proposals for private hire vehicles would artificially restrict competition, and so stood to curb developments that benefited the paying passenger (4). For the first time, the disruptive innovator Uber was winning public backing from a prominent member of the regulatory 'establishment,' and in a manner that portrayed TfL as reactionary and threatening to curb an innovative and publicly popular service. The political and public image of Uber was therefore shifting from being an invasive threat to established services, to being an efficient innovator that was offering a new and distinctive service.

In January 2016, TfL abandoned its plans to tighten regulations on private hire vehicles. This represented a major victory for Uber, which had demonstrated that it could out manoeuvre politically both TfL and the black cab operators. To add to this, TfL remained frustrated at the government's refusal to cap the numbers of private hire vehicles in central London. London Mayor Boris Johnson claimed that the numbers of private hire vehicles in the central London congestion charging zone had increased by more than fifty per cent in the previous two years. He argued that this was causing serious congestion, and so defeating the object of the congestion charge.

Consequently, he was asking TfL to investigate the impact and feasibility of removing the congestion charging exemption for private hire vehicles (5). Once more, however, this proposal confronted Johnson and TfL with the accusation of placing unfair competitive burdens on operators such as Uber, The public and official support the 
company was winning had already demonstrated its skill in resisting restrictions on its operations.

\section{The Limits to Disruptive Innovation in London}

As 2016 progressed, however, Uber faced fresh challenges to its operations from both TfL and also its own employees in London, and this time found it more difficult to prevail. It could be said that Uber was beginning to experience some of the penalties of success in that, as its growth continued, official concern increased about what would be the long-term impacts in terms of the operations themselves, and on employment patterns. Ironically, the very success of the disruptive innovator strategy created political and legal limits in terms of the degree to which it could be allowed to continue unchecked. In operational terms, the rise of Uber is graphically illustrated in that, by August 2016, there were over 110,000 cars in London licensed to operate as private hire vehicles. Of these, around 30,000 were Uber vehicles. Meanwhile, the number of black cabs, at around 22,500, remained about the same as in 2011, the year before the introduction of Uber (6).

TfL was compelled to accept the success of Uber and other private hire operators, but at the same time there were now real fears about the future identity and existence of the black cabs, which were widely considered to be an indispensable and iconic element of London's identity. These concerns made it more difficult for Uber to define the direction of the political debate. In practical terms, there was also the politically sensitive issue of the employment prospects for the black cab drivers. In May 2016, the Conservative Boris Johnson was replaced as London Mayor by the Labour Party's Sadiq Khan, who wasted little time in producing a Taxi and Private Hire Action Plan (7). This Plan was broadly sympathetic to the black cabs, and its recommendations included giving the black cabs access to twenty more bus lanes, and quadrupling the number of officials enforcing private hire regulations. In addition, restrictions on private hire vehicles included the requirement that operators must have a London-based, twenty-four hour call centre. Such a requirement would be a handicap to Uber with its app based operations. Operators would also be required to have permanent commercial insurance, while there would be a written English test for all drivers.

The black cab operators had fought against Uber since the latter's introduction in 2012, but with little success in stemming the tide of its advance, so that in four years Uber had risen from nothing to having considerably more vehicles on the road than the black cabs. The new Mayor's proposals, however, gave them hope that some degree of help was at hand. As with the 2015 proposals, Uber made a public appeal for support, and in addition took its case to the High Court. On this occasion, the court endorsed TfL's case for the English language tests, but found in Uber's favour in the case of permanent commercial insurance and maintaining a call centre. At least in the case of the English test, therefore, the needs of the black cabs were given precedence. The image of Uber was also affected around this time by accusations concerning its alleged failure to pay taxes in the UK. Nevertheless, there was no suggestion that the new measures would have a significant impact on the continued advance of Uber, and significantly a 2016 Report by Nick Ferrari for the centre-right think tank Policy Exchange, Saving the Black Cab (8), criticised the black cab operators for attempting to conquer Uber by means of seeking to protect their own interests. Instead, it advised 
the black cabs to come to terms with the fact that the market had changed, and that they could only survive by competing more effectively in their own right on price and convenience in the new world. As the disruptive innovator, Uber had set the operational and political agenda, and the black cabs and $\mathrm{TfL}$ had been compelled to respond.

For its part, Uber needed to develop and promote its distinctive style and image as an innovator, and this required being continually on the move in terms of the range and types of services it provided. In terms of geographical scale, in 2016 it more than doubled the scope of its operations in London. Previously, it had been restricted to the city centre, but now expanded to more of the outer areas, including Heathrow Airport. In this case, Uber was hoping to attract more commuters to its services, but it could also be said that it was again keeping one step ahead of the regulator in terms of threatened restrictions on its operations in the central congestion charging zone. One of the consistent selling points of Uber has been that the spread of its services could lead to a reduction in car ownership, although in congestion terms this could be countered by the greater number of private hire vehicles on the road. To help counter this charge, Uber introduced its ride sharing service UberPool to London in 2015. This allowed the app technology to match passengers going in the same direction, so that by sharing a ride a significant saving could be made compared with the established UberX service (although UberPool could also be seen as a threat to bus services). Uber also extended its range by entering the food delivery market by means of bike and scooter through UberEats.

Ironically, Uber's greatest point of vulnerability in London has occurred with the treatment and status of its own drivers. The fundamental 'sharing economy' element of the Uber operation is that the drivers use their own vehicles and download the Uber app. As we noted earlier, Uber chooses to treat its own drivers as 'registered partners' rather than company employees, but this has led to persistent tensions with its own drivers, who seek to be official company employees with the associated benefits. In addition, Uber typically takes a 25 per cent commission on each ride, and this has led to complaints from drivers about their incomes being squeezed, resulting in protests and legal cases in several European countries and United States cities. London has been no exception to these trends, and in 2015 a protest was held, supported by the GMB union, concerning falling incomes for the drivers, partly through Uber increasing its commission rates, and what were claimed to be falling fares.

A 2016 survey suggested that more than half of Uber's London drivers made money through other jobs, and that Uber was not the biggest source of pay for one in five drivers (9). This type of multiple employment has become commonly known as the 'gig economy,' with increasing numbers of people less reliant on a single job and employer. Anxieties about the conditions of employment have become widespread, particularly in the courier and urban freight sectors. Although the 'gig economy' might open up new employment opportunities, there is increasing political concern about its consequences in terms of pay and conditions.

Uber found itself at the forefront of this debate in 2016, when two of its drivers, again backed by the GMB union, took their case to the Central London Employment Tribunal, claiming that they should be treated as employees of Uber, and given associated benefits such as sickness and holiday pay. The Tribunal ruled in favour of 
the drivers, and in its judgement stated that, the notion that Uber in London was a mosaic of 30,000 small businesses, linked by a common 'platform,' was to their minds faintly ridiculous. For its part, Uber decided to appeal against the ruling, asserting that tens of thousands of people in London drove with Uber precisely because they wanted to be self-employed and their own boss. The Uber case attracted widespread attention, and significantly around this time Prime Minister Theresa May asked Matthew Taylor, the former policy chief of former Prime Minister Tony Blair, to examine how to extend workers' rights in the 'gig economy,' and so maintain flexibility, while also supporting security and workforce rights. The business models to be examined included Uber. The scale and character of its operations now firmly occupied the attention of people in the highest places, but the employment tribunal judgement was an indicator to Uber that there could be limitations to its strategy and style.

\section{Maintaining Momentum as a Disruptive Innovator?}

Uber has rapidly achieved huge growth, while generally retaining a status as a market disruptive innovator. The technology it has adopted has been innovative, although not unique, but its success has been derived from a global strategy, backed up by large capital injections, that maintains a relentless pursuit of market growth through overriding, or even bypassing, established interests and regulatory systems. The guiding motto of chief executive Travis Kalanick of 'it is easier to ask for forgiveness than permission,' has served it well, but as it becomes one of the world's corporate giants, with ambitions to match, can it maintain its expansionary momentum as a disruptive innovator?

In London, Uber was able to launch a politically sophisticated campaign in winning public and business support when it was threatened with tighter regulation. Its fares might be extensively subsidised, but its success was based on an operation undoubtedly popular with the public, and with modern 'techno-optimism' at its heart. Nevertheless, on a wider scale, the company appears to have accepted that it needs political allies if it is to continue its rate of growth. In particular, in 2016 Uber appointed an eight person advisory board that contained a former EU commissioner, a former United States transport secretary, a former campaign manager for former US President Barack Obama, a former prime minister of Peru, and a Saudi Arabian princess (10). However, in 2017 Uber's image was damaged by revelations concerning its secret Greyball programme, whereby the company would identify users who might be rivals and enforcement officials, and show them a fake version of its app whenever they tried to order a car, thereby frustrating any official action. In response, Uber announced that it was reviewing the programme, and banning employees from using Greyball to target regulators. Around this time, Uber was also subject to sexual harassment claims by a former employee, and a recorded altercation between Travis Kalanick and an Uber driver with regard to employment conditions. All these revelations damaged Uber's image as an innovator, and cast it in a more reactionary light.

At the same time, Uber's ambitions show no signs of slackening. Its long-term aims are reflected in Kalanick's stated mission for Uber to 'provide transportation as reliable as running water, everywhere for everyone.' The scale of these ambitions goes beyond the transport sector, and includes major impacts on society as a whole. 
For example, in the US Uber has established partnerships with a range of municipalities to offer privately run services to replace former public sector operations. These include such statutory functions as transport for the disabled. As part of these partnerships, local authorities offer discounts to citizens who use Uber (11). In taking on these partnerships, companies such as Uber can blur the distinction between the public and private sectors, while making themselves indispensable to local authorities and communities.

Perhaps the most ambitious element in Uber's strategy, however, is its drive to develop autonomous vehicles. In 2015, Uber opened a driverless car research centre in Pittsburgh in the United States, and in September 2016 launched a self-driving taxi fleet in the city (although retaining a 'driver' for legal and safety purposes). In doing so, Uber placed itself ahead of intense competition for developing driverless vehicles from companies such as Alphabet (the parent of Google), Tesla, Ford, and GM. In association with such developments as autonomous vehicles, Uber is also developing its own global mapping system. Linked to its autonomous vehicle programme, in 2017 Alphabet sued Uber on the grounds of trade secret theft.

Nevertheless, in December 2016 Uber introduced self-driving taxis in its home city of San Francisco. On this occasion it reverted to its disruptive innovator strategy by putting the vehicles on the streets without the required official permits. In this way, the company did not need to disclose safety statistics. This decision rebounded on the company when a few days later the California highways regulator ordered Uber to take its vehicles off the road (12). In 2017, Uber reversed its decision, and decided to apply for the permits.

Such setbacks are unlikely to deter Uber from its long-term goals, with major implications for vehicle manufacture and patterns of ownership, the identity and relationships between the public and private sectors, and the structure and character of the employment market. By exploiting its position as a disruptive innovator it has acted as a major agent of change, and in doing so placed itself in a position of commensurate political and public influence.

\section{Acknowledgement}

This article forms part of the research project: 'The Governance of Transitions in Urban Mobility: The Case of Uber in London' funded by the Rees Jeffreys Road Fund. Tim Schwanen's contribution has been made possible by a grant from the UK Research Councils (EP/K011790/1) to the Centre on Innovation and Energy Demand. We would like to thank Jeremy Richardson and Antje Witting for their valuable comments on earlier drafts of this article.

\section{Notes}

1. Christensen, C. The Innovator's Dilemma, Boston, MA, Harvard Business School Press, 1997.

\section{Financial Times, 12 June 2014.}

3. Ibid, 21 May 2015. 
4. The Guardian, 5 December 2015.

5. Ibid, 21 January 2016.

6. Financial Times, 14 September 2016.

7. Mayor of London, Taxi and Private Hire Action Plan 2016, London, Transport for London, 2016

8. Nick Ferrari, Saving the Black Cab. Why Black Taxis are Vital to London's

Economy and Identity, London, Policy Exchange, Capital City Foundation, 2016.

9. The Times, 3 June 2016.

10. The Guardian, 16 December 2016.

11. The Observer, 11 September 2016.

12. Financial Times, 23 December 2016. 